REVISTA DE GEOCIÊNCIAS DO NORDESTE

Northeast Geosciences Journal

v. $7, n^{\circ} 1(2021)$

ISSN: $2447-3359$

https://doi.org/10.21680/2447-3359.2021v7n1ID21251

\title{
AS SECAS E SUAS CONSEQUÊNCIAS SOBRE OS RECURSOS DO SEMIÁRIDO BRASILEIRO
}

\begin{abstract}
Sérgio Murilo Santos de Araújo ${ }^{1}$
${ }^{1}$ Professor Associado da Unidade Acadêmica de Geografia, Centro de Humanidades - Universidade Federal de Campina Grande (UFCG), Campina Grande-PB, Brasil.

ORCID: https://orcid.org/0000-0001-9599-4383

E-mail: sergiomurilosa.ufcg@gmail.com

\section{Resumo}

O presente texto teve como objetivo discutir as secas da região Semiárido Brasileiro nos seus aspectos ambientais, sociais e econômicos com destaque para a última seca ocorrida entre os anos de 2012-2017. O texto é o resultado da apresentação na mesa redonda "As secas e a desertificação no semiárido brasileiro" no I Simpósio de Redução de Riscos dos Desastres na Região Nordeste e II Workshop do Grupo de Pesquisas de Gerenciamento dos Riscos de Desastres - GENAT. O texto produzido justifica-se pela demanda requerida pelo evento e pelo compromisso do autor em apresentá-lo. Como consideração final destaca-se que aliar o conhecimento científico às políticas de estado sempre será necessário, uma vez que as medidas de mitigação dos impactos e a preparação aos fenômenos naturais requer uma população conhecedora e atuante nas crises (formação de cidadãos resilientes) num país onde a democracia deve ser a base da sociedade.
\end{abstract}

Palavras-chave: Secas; Semiárido Brasileiro; Terras secas.

\section{DROUGHTS AND THEIR CONSEQUENCES ON THE RESOURCES OF THE BRAZILIAN SEMIARID}

\footnotetext{
Abstract

This text aimes to discuss the droughts of the Brazilian Semi-Arid region in its environmental, social and economic aspects, with emphasis on the last drought that occurred between the years 2012-2017. The text is the result of the presentation at the round table "Droughts and desertification in the Brazilian semiarid" at the I Symposium on Disaster Risk Reduction in the Northeast Region and II Workshop of the Research Group on Disaster Risk Management - GENAT. The text is justified by the demand of the event and by the author's commitment to present it. As a final consideration, it is noteworthy that combining scientific
}

knowledge with state policies will always be necessary, since measures to mitigate impacts and prepare for natural phenomena require a knowledgeable and active population in crises (training of resilient citizens) in a country where democracy should be the basis of society.

Keywords: Doughts; Brazilian Semiarid; Dry lands.

\section{SEQUÍAS Y SUS CONSECUENCIAS SOBRE LOS RECURSOS DEL SEMIÁRIDO BRASILEÑO}

\section{Resumen}

Este texto tuvo como objetivo discutir las sequías de la región semiárida brasileña en sus aspectos ambientales, sociales y económicos, con énfasis en la última sequía que ocurrió entre los años 2012-2017. El texto es el resultado de la presentación en la mesa redonda: "Sequías y desertificación en el Semiárido brasileño" en el I Simposio sobre Reducción del Riesgo de Desastres en la Región Nordeste y II Taller del Grupo de Investigación sobre Gestión del Riesgo de Desastres - GENAT. El texto se justifica por la demanda del evento y el compromiso del autor de presentarlo. Como consideración final, cabe destacar que siempre será necesario combinar el conocimiento científico con las políticas estatales, ya que las medidas para mitigar los impactos y prepararse para fenómenos naturales requieren una población conocedora y activa en crisis (formación de ciudadanos resilientes) en un país donde la democracia debe ser la base de la sociedad.

Palabras-clave: Sequía; Semiárido brasileño; Tierra seca.

\section{INTRODUÇÃO}

As terras secas (que compreendem as zonas áridas, semiáridas e subúmidas secas) apresentam como característica comum o fenômeno climatológico das secas, que pode ser caracterizado sumariamente por uma quantidade de chuvas inferior à média anual de um dado lugar. A seca pode ser entendida como um fenômeno natural que consiste na ausência ou redução de precipitações inferiores à média anual em uma dada localidade ou região, que acarreta déficit(escassez) na disponibilidade de água tanto para as atividades humanas como para a atividade biológica dos seres vivos (BARRY e CHORLEY, 2013). Quanto à duração 
pode ser temporária, pois tem uma duração, não sendo permanente, mas com severidade e frequência incertas e ocorrência imprevisível ou difícil de se predizer (PEREIRA, 2002).

Embora na prática qualquer lugar possa passar por uma seca, estas ocorrem com maior intensidade e frequência nas regiões subúmidas e semiáridas geralmente trazendo problemas sociais, econômicos e ecológicos-naturais. Nas regiões que margeiam os desertos ou nas terras semiáridas e subúmidas secas, a seca é um fenômeno comum, onde se tem como exemplos mais críticos o Sahel, no continente africano, a região do Semiárido Brasileiro (SAB), o Mediterrâneo Europeu entre outras.

Todas as áreas submetidas a climas onde persiste um período seco mais longo que o chuvoso, ou mesmo naqueles em que as precipitações são escassas e irregulares ao longo do tempo, a disponibilidade de água é um agravante para a produção econômica, principalmente na agropecuária e na agricultura de subsistência. No SAB o fenômeno das secas é recorrente e tem registros desde o período colonial, como será descrito mais adiante. Devido ao conjunto de condições naturais e socioeconômicas, os impactos das secas foram sempre bem severos para a população do $\mathrm{SAB}$, trazendo fome e sede em função da escassez da água e baixa produção de alimentos.

O presente texto tem como objetivo discutir as secas como fenômeno climático, econômico e social, particularmente na região do $\mathrm{SAB}$. O texto aborda aspectos históricos e os principais conceitos relativos ao tema como clima, vulnerabilidade e crise hídrica. Deve-se dizer que não se trata de um texto finalizado, mas em construção, uma vez que o tema (das secas) é motivo de pesquisa do autor há algum tempo e, particularmente, este texto deriva de uma apresentação em mesa redonda e que carece de maiores aprofundamentos.

Vale salientar que o presenes texto foi resultado da apresentação na mesa redonda "As Secas e a Desertificação no Semiárido Brasileiro" no I Simpósio de Redução de Riscos dos Desastres na Região Nordeste e II Workshop do Grupo de Pesquisas de Gerenciamento dos riscos de Desastres - GENAT. A mesa foi realizada no dia 06 de novembro de 2019, no Campus de Caicó-RN, da Universidade Federal do Rio Grande do Norte UFRN.

\section{SECAS E TERRAS SECAS}

Secas podem ser caracterizadas ou definidas, do ponto de vista climato-meteorológico, como "uma estiagem prolongada, caracterizada por provocar uma redução sustentada das reservas hídricas existentes" (CASTRO et al., 2003, p. 59).

As secas podem ser designadas em função dos fatores naturais ou ecológicos que as causam como: 1) Clima da região; 2) Distribuições espacial e temporal das precipitações; 3) Capacidade de armazenamento de água pelo solo; 4) Flutuações dos lençóis freáticos subterrâneos; e 5) Qualidade de água armazenada à superfície ou corrente.

De modo geral, as secas são classificadas em quatro categorias, de acordo com seus efeitos, e podem ser: Meteorológica, Agrícola, Hidrológica e Socioeconômica (Figura $1)$.

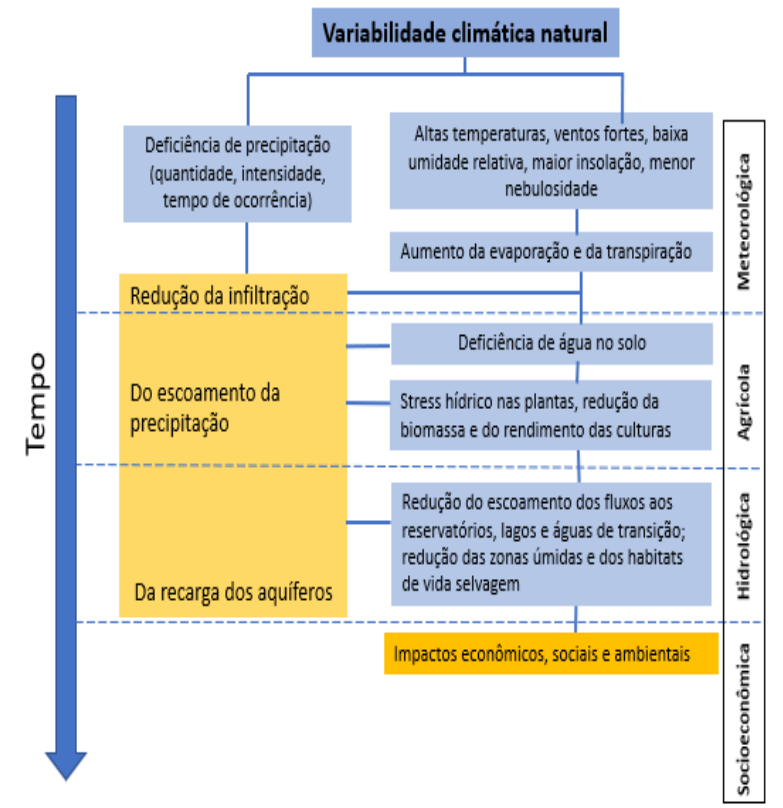

Figura 1 - Tipos de secas. Fonte: Azevedo (2013).

A seca meteorológica resulta do efeito de fenômenos atmosféricos na redução da pluviometria de uma região. A seca agrícola ocorre quando as disponibilidades hídricas do solo são inadequadas ou insuficientes para atender à demanda evaporativa dos campos cultivados. A seca hidrológica refere-se a períodos com níveis dos fluxos superficiais de água (rios, riachos e córregos) e dos reservatórios abaixo do normal. E, por fim, a seca socioeconômica que está associada ao efeito conjunto dos impactos naturais e sociais que resultam da falta de água, devido ao desequilíbrio entre o fornecimento e a procura do recurso água (AZEVEDO, 2013).

Entre os anos de 2012 e 2017 a situação dos recursos hídricos no SAB atingiu um nível crítico. Para se ter ideia, no estado da Paraíba apenas os reservatórios das bacias situadas na região da Mata e Litoral possuía capacidades de armazenamento superiores a 30\%, quando comparadas com suas capacidades instaladas, enquanto nas demais regiões situadas no Agreste, Borborema e Sertão se encontravam com menos de $15 \%$ de suas reservas hídricas (MEDEIROS e BRITO, 2017).

A crise hídrica no SAB aconteceu não somente devido ao fator climático, explicado pelo El Niño, mas pela demanda aumentada na região em função do crescimento populacional, do boom econômico e da construção civil. Principalmente na região de Campina Grande-PB, onde se constatou o uso da água fornecida pela CAGEPA (Companhia de Água e Esgotos da Paraíba) nas atividades de construção civil do município, que é abastecida pelo Açude Epitácio Pessoa (Boqueirão), sendo este o maior manancial da região (ARAÚJO, 2018).

\section{TERRAS SECAS E O SEMIÁRIDO BRASILEIRO}

As terras secas apresentam como característica comum o fenômeno climatológico das secas, que pode ser caracterizado por uma quantidade de chuvas inferior à média anual de um lugar. 
Isso pode se dar em um ano ou em anos seguidos ou alternados. Mesmo que um ano tenha precipitações dentro das medias anuais, existe um período seco e outro chuvoso nas áreas de terras secas, tendo tal período seco geralmente uma duração maior em mese durante $\mathrm{o}$ ano. As terras secas representam as áreas áridas, semiáridas e subúmidas secas, com médias pluviométricas que podem chegar até $1.000 \mathrm{~mm}$ de médias anuais.

A região do Semiárido Brasileiro foi delimitada diversas vezes em função de políticas públicas. Hoje ela comporta 1.262 municípios, em uma área de territorial de $1.128 .697 \mathrm{Km}^{2}$ e sua população foi estimada em 27.870.241 habitantes em 2017 (SUDENE, 2017). No SAB as secas é um fenômeno comum e responsável por desastres ao longo de mais de cinco séculos (REGO, 2012).

A busca das explicações sobre o fenômeno das secas levou a um fenômeno de circulação atmosférica global, verificando-se que os períodos nos quais havia a redução dos totais anuais pluviais abaixo das médias no Nordeste do Brasil estão relacionados ao fenômeno El Niño (GIRÃO, 2012).

O El Niño é um fenômeno resultante da interação atmosferaoceano na zona tropical, caracterizado pelo aquecimento anormal das águas superficiais do oceano Pacífico, provocando anomalias como padrões de circulação dos ventos em nível mundial e alterações no regime de chuvas na América do Sul (GIRÃO op. cit.; INPE, 2016).

Em anos de El Niño ocorre alteração no regime de chuva em grande parte da região equatorial, que no Nordeste do Brasil responde por uma forte redução da precipitação. Simplificando, Caviedes (2001 apud GIRÃO, 2012) assinala que:

O aparecimento de um episódio de El Niño ocorre quando a célula de alta pressão sobre o Atlântico tropical intensifica-se, o que impede o deslocamento para Sul das altas pressões associadas à Convergência Intertropical: é esta a causa das secas no NE do Brasil. Quando os períodos de estiagem ocorrem durante apenas um verão, são consideradas simplesmente como secas resultantes de uma atuação incipientes, e/ou concomitantemente tardia, dos sistemas atmosféricos atuantes na estação, sendo resultante de um fenômeno El Niño considerado fraco. Contudo, quando os baixos índices pluviais se propagam desde o verão anterior ao próximo, a estiagem prolongada (superior a um ano, podendo chegar a mais de três anos) é creditada as influências do fenômeno El Niño de atuação moderada a forte (CAVIEDES, 2001 apud GIRÃO, p. 37).

As áreas com maior incidência das Secas no Nordeste são aquelas que estão localizadas no litoral norte da região Nordeste, onde a atuação da Convergência Intertropical (CIT) avançando ao sul entra no interior do SAB e vai provocar chuvas, o que depende da ausência do El Niño. O que acontece é uma condição citada anteriormente (CAVIEDES, op. cit.): "[...] quando a célula de alta pressão sobre o Atlântico tropical intensifica-se, o que impede o deslocamento para Sul das altas pressões associadas à Convergência Intertropical[...]".

Na Figura 2 observa-se que a maior área de incidência das secas está sobre os Estados do Ceará, Rio Grande do Norte Paraíba, Pernambuco e Piauí.

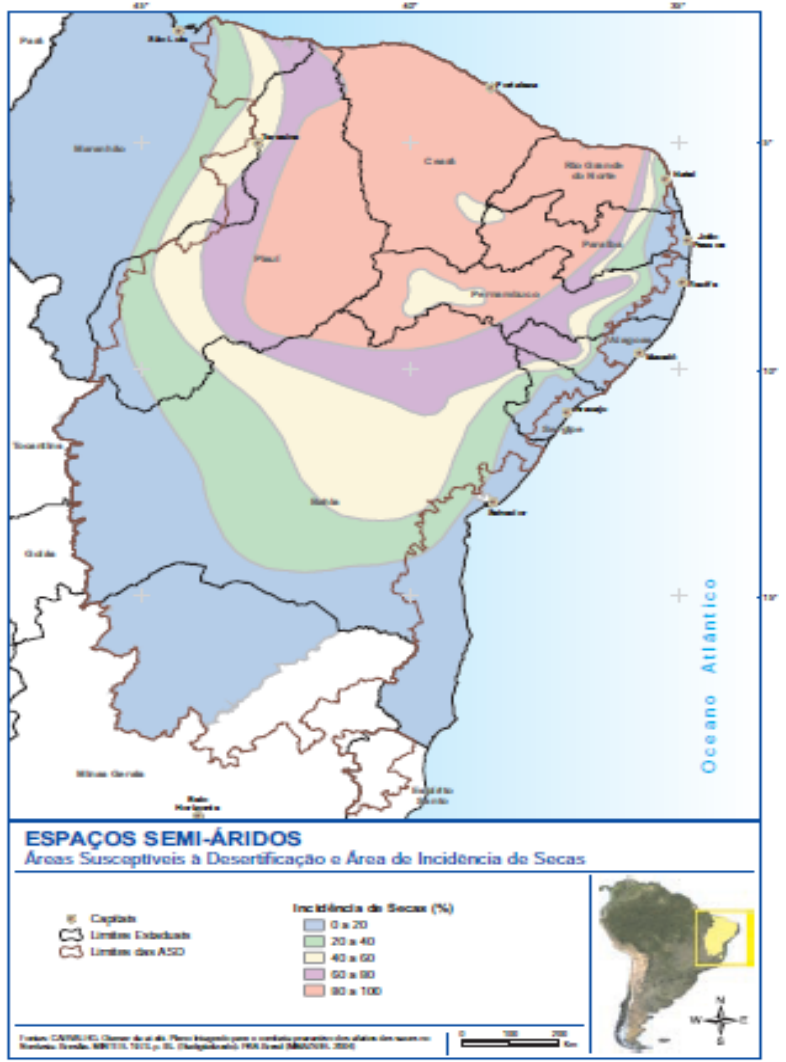

Figura 2 - Incidência das Secas no Nordeste. Fonte: MMA (2007).

Os impactos decorrentes de uma seca sobre a sociedade dependem de um conjunto de condições sociais, econômicas e ambientais. Normalmente a condição socioeconômica define a vulnerabilidade socioambiental das comunidades atingidas pelas secas.

Como mostrado na Figura 3, a capacidade de lidar com o fenômeno climático/ambiental depende da capacidade adaptativa da comunidade, quanto maior for essa capacidade menor é a vulnerabilidade do grupo social ou comunidade.

A vulnerabilidade, maior ou menor, está relacionada com a situação de como está preparada uma comunidade ou a sua capacidade de lidar com a ocorrência do fenômeno, ou seja, a resiliência - que é essa capacidade. Ainda, pode-se dizer que quanto mais preparados estão os cidadãos em lidar com o fenômeno melhor passam por uma situação de crise, podendo ter mecanismos de convivência com a situação. 


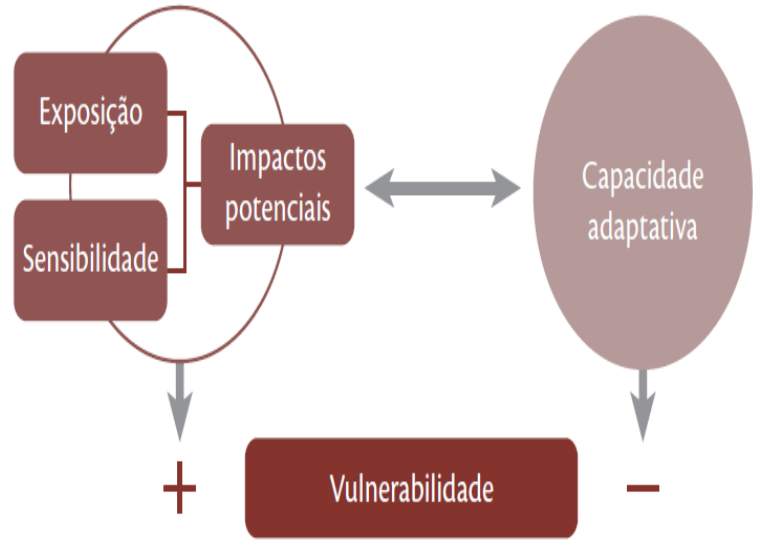

Figura 3 - Componentes para definição da vulnerabilidade climática. Fonte: Suassuna (2019).

Nas duas últimas décadas, a situação foi melhorada no Nordeste do Brasil (NEB) com as políticas de convivência com a seca através de tecnologias sociais, como as cisternas de placas e outros, primeiramente com as Organizações NãoGovernamentais (ONGs) e depois com o Estado através de Políticas e Programas, como exemplo o Programa um Milhão de Cisternas - P1MC, do governo federal.

\section{PEQUENO HISTÓRICO DAS SECAS}

No Brasil as primeiras secas foram registradas no período colonial, ainda no século dezesseis. A primeira foi mencionada, em 1553, pelo Padre João de Azpilcueta, da Companhia de Jesus, que relatou danos às cabeceiras dos rios Jequitinhonha e São Francisco; no mesmo século, a segunda seca foi registrada, em 1559, pelo Padre Serafim Leite, na História da Companhia de Jesus no Brasil, na então Província da Bahia. A terceira se deu em 1583, nesta o Jesuíta Fernão Cardim relatou uma seca que ficou conhecida por forçar o deslocamento de aproximadamente 5 mil índios da região dos Cariris Velhos, dos agrestes e dos sertões interiores para o litoral, em busca de alimentos (REGO, 2012; ARAÚJO e LIMA, 2019).

Durante o reinado de Dom Pedro II ocorreu a seca de maior impacto socioeconômico, a seca de 1877-78-89, quando vieram a óbito 500 mil nordestinos sendo a maior parte do Estado do Ceará (estimado em cerca de 300 mil óbitos), mas sem registros históricos até o momento que demonstre tal estimativa. Fato marcante nas políticas públicas voltadas às secas se deu no início do século XX, quando o presidente Nilo Peçanha criou em 1909 a Inspetoria de Obras Contra as Secas (IOCS) através do Decreto $\mathrm{n}^{\circ} 7.619$, de 21 de outubro, a partir daí tem início uma política de obras de engenharia contra as secas (ARAÚJO e LIMA, op. cit.).

No Quadro 1 observa-se uma cronologia das secas no NEB baseada em pesquisa bibliográfica, onde são apresentados os anos ou período de ocorrência e sua intensidade. Destacam-se as secas mais prolongadas como a dos anos 1877-1879, a de 1979-1983, que ficou bem conhecida devido à grande divulgação pelos meios televisivos dos conflitos, como saques de alimentos e ações como as frentes de trabalho e a última de 2012-2017. Todas com intensidade de moderada a forte.
Quadro 1 - Secas no Semiárido Brasileiro - séculos 16 a 21

\begin{tabular}{|c|c|c|c|c|c|}
\hline Ano & Intensidade & Ano & Intensidade & Ano & $\begin{array}{c}\text { Intensi- } \\
\text { dade }\end{array}$ \\
\hline 1553 & Fraca & 1804 & Fraca & 1958 & Fraca \\
\hline 1559 & Fraca & $1809-10$ & $\begin{array}{l}\text { Moderada a } \\
\text { Forte }\end{array}$ & 1962 & Fraca \\
\hline 1583 & Fraca & 1816 & Fraca & 1966 & Fraca \\
\hline 1587 & Fraca & $1824-25$ & $\begin{array}{l}\text { Moderada a } \\
\text { Forte }\end{array}$ & 1970 & Fraca \\
\hline 1603 & Fraca & 1827 & Fraca & $\begin{array}{l}1979- \\
83\end{array}$ & $\begin{array}{l}\text { Moderada a } \\
\text { Forte }\end{array}$ \\
\hline 1614 & Fraca & 1830 & Fraca & $\begin{array}{l}1990- \\
93\end{array}$ & $\begin{array}{l}\text { Moderada a } \\
\text { Forte }\end{array}$ \\
\hline 1692 & Fraca & 1833 & Fraca & $\begin{array}{l}1998- \\
99\end{array}$ & $\begin{array}{l}\text { Moderada a } \\
\text { Forte }\end{array}$ \\
\hline 1710-11 & \begin{tabular}{|l|} 
Moderada a \\
Forte \\
\end{tabular} & $1844-45$ & $\begin{array}{l}\text { Moderada a } \\
\text { Forte }\end{array}$ & $\begin{array}{l}2001- \\
02\end{array}$ & Fraca \\
\hline 1721 & Fraca & $1877-79$ & $\begin{array}{l}\text { Moderada a } \\
\text { Forte }\end{array}$ & 2005 & Fraca \\
\hline 1723-27 & \begin{tabular}{|l|} 
Moderada a \\
Forte \\
\end{tabular} & $1888-89$ & $\begin{array}{l}\text { Moderada a } \\
\text { Forte }\end{array}$ & $\begin{array}{l}2007- \\
2008 \\
\end{array}$ & Moderada \\
\hline 1736-37 & $\begin{array}{l}\text { Moderada a } \\
\text { Forte }\end{array}$ & 1891 & Fraca & 2010 & Fraca \\
\hline $1744-45$ & \begin{tabular}{|l|} 
Moderada a \\
Forte \\
\end{tabular} & 1893 & Fraca & $\begin{array}{l}2012- \\
2017 \\
\end{array}$ & Forte \\
\hline 1754 & Fraca & 1900 & Fraca & 2018 & Chuvoso \\
\hline 1760 & Fraca & 1903 & Fraca & 2019 & Chuvoso \\
\hline 1772 & Fraca & 1915 & Fraca & 2020 & Chuvoso \\
\hline 1774 & Fraca & 1919 & Fraca & 2021 & $?$ \\
\hline $1777-78$ & $\begin{array}{l}\text { Moderada a } \\
\text { Forte } \\
\end{array}$ & 1932 & Fraca & 2022 & $?$ \\
\hline 1784 & Fraca & 1942 & Fraca & 2023 & $?$ \\
\hline $1790-93$ & $\begin{array}{l}\text { Moderada a } \\
\text { Forte } \\
\end{array}$ & $\begin{array}{l}\text { 1951-52- } \\
53\end{array}$ & Forte & $\ldots$ & $\ldots$ \\
\hline
\end{tabular}

Fonte: Elaborado pelo autor com base em pesquisa bilbiografica.

Deve-se salientar que as secas são fenômenos cíclicos ligados à dinâmica natural, restando a sociedade planejar a convivência com o fenômenos e se adaptar à sua ocorrência com políticas e programas de Estado. Estes devem perpassar a história da política partidária, não sendo obra de um ou de outro governante, mas de continuidade do que deu certo para a maioria da população que vive numa região acometida por esses fenômenos.

\section{IMPACTOS DA SECA DE 2012-2017 NAS PRINCIPAIS CULTURAS DA AGRICULTURA NO SEMIÁRIDO DO NORDESTE BRASILEIRO}

A seca do período 2012-2017 foi considerada como uma das maiores secas nos últimos 50 anos, muito mais pelo tempo de ocorrência do que pelos impactos. No entanto, o período posterior a ela, nos anos 2018 e 2019, apresentou chuvas acima da média na maior parte do SAB e NEB. Também deve ser chamado atenção de que as previsões para o ano de 2020 ainda em curso estão dentro ou acima das médias no conjunto do SAB. Entretanto, em algumas regiões dentro do $\mathrm{SAB}$ têm persistido uma seca localizada em função de chuvas ainda abaixo da média.

Como pode ser observado na Figura 4, ao longo dos anos 2012-2017 as chuvas no NEB situaram-se abaixo das médias anuais. Isso trouxe consequências na produção de alimentos, principalmente relacionadas às culturas tradicionais de produção 
e consumo regional, como são os casos de feijão, milho e mandioca.

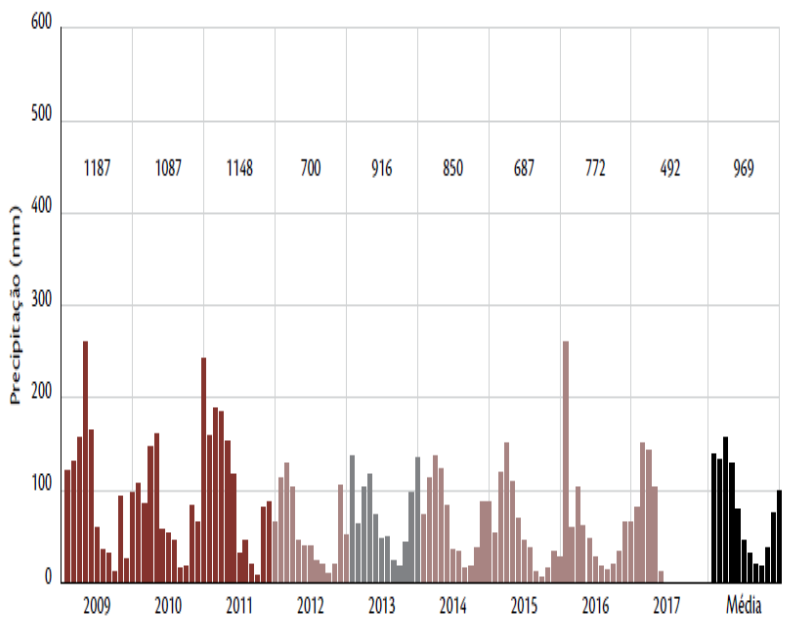

Figura 4 - Distribuição das chuvas no Nordeste e média anual, 2009-2017. Fonte: Lima e Magalhães (2018).

As tabelas a seguir mostram as produções das principais culturas do Semiárido: feijão, mandioca e milho. O feijão é um alimento muito importante na alimentação do brasileiro e base da nutrição do nordestino; essa cultura, assim como outras também importantes, teve queda na produção em todos os estados nordestinos da região $\mathrm{SAB}$.

As Tabelas 1 e 2 mostram a produção de feijão, em comparação entre a média dos anos 2009/2010 e a produção ao longo dos anos 2011 a 2016, sendo observado que a queda na produção de feijão foi devido à seca persistente. Tal queda se deu em todos os estados a partir do ano de 2012 até 2016. Na Tabela 2 destaca-se a variação percentual dessa produção ao longo dos anos.

Tabela 1 - Produção de Feijão no SAB - 2011-2016

\begin{tabular}{|l|r|r|r|r|r|r|r|}
\hline \multirow{2}{*}{ UF } & \multicolumn{7}{|c|}{ Produção (em mil t) } \\
\cline { 2 - 9 } & $\begin{array}{l}\text { MÉDIA } \\
\mathbf{2 0 0 9 / 1 0}\end{array}$ & $\mathbf{2 0 1 1}$ & $\mathbf{2 0 1 2}$ & $\mathbf{2 0 1 3}$ & $\mathbf{2 0 1 4}$ & $\mathbf{2 0 1 5}$ & $\mathbf{2 0 1 6}$ \\
& & & & & & \\
\hline AL & 24,84 & 15,39 & 1,28 & 8,64 & 9,85 & 5,92 & 0,71 \\
\hline BA & 244,26 & 117,50 & 30,16 & 163,40 & 156,37 & 204,37 & 73,45 \\
\hline MG & 95,37 & 235,07 & 41,06 & 44,87 & 93,11 & 54,47 & 46,99 \\
\hline PB & 32,97 & 21,70 & 21,05 & 14,15 & 15,78 & 13,69 & 17,60 \\
\hline PE & 26,30 & 32,31 & 2,11 & 14,57 & 13,84 & 4,85 & 6,91 \\
\hline PI & 96.71 & 104,45 & 16,89 & 40,35 & 51,99 & 33,02 & 23,64 \\
\hline RN & 304,55 & 200,70 & 127,80 & 40,17 & 42,86 & 128,49 & 80,34 \\
\hline SE & 13,57 & 30,31 & 1,81 & 7,33 & 9,05 & 3,37 & 2,76 \\
\hline F Onte: & 25,54 & 7,53 & 3,00 & 14,66 & 6,98 & 5,18 & 1,61 \\
\hline
\end{tabular}

Fonte: MAPA (2017).
Tabela 2 - Variação da Produção de Feijão no SAB - 2011-2016

\begin{tabular}{|c|c|c|c|c|c|c|}
\hline \multirow{2}{*}{ UF } & \multicolumn{6}{|c|}{ VARIAÇ̃̃O \% (base média 2009/10) } \\
\cline { 2 - 7 } & $\mathbf{2 0 1 1}$ & $\mathbf{2 0 1 2}$ & $\mathbf{2 0 1 3}$ & $\mathbf{2 0 1 4}$ & $\mathbf{2 0 1 5}$ & $\mathbf{2 0 1 6}$ \\
\hline AL & $-38,03$ & $-94,84$ & $-65,24$ & $-60,35$ & $-76,17$ & $-97,16$ \\
\hline BA & $-51,90$ & $-87,65$ & $-33,11$ & $-35,98$ & $-16,33$ & $-69,93$ \\
\hline CE & 146,47 & $-56,94$ & $-52,96$ & $-2,37$ & $-42,89$ & $-50,73$ \\
\hline MG & $-34,19$ & $-36,15$ & $-57,09$ & $-52,12$ & $-58,8$ & $-46,61$ \\
\hline PB & 22,85 & $-91,99$ & $-44,59$ & $-47,37$ & $-81,58$ & $-73,62$ \\
\hline PE & 8,01 & $-82,54$ & $-58,28$ & $-46,24$ & $-65,85$ & $-75,55$ \\
\hline PI & $-34,10$ & $-58,04$ & $-86,81$ & $-85,93$ & $-57,81$ & $-73,62$ \\
\hline RN & 123,32 & $-86,69$ & $-45,99$ & $-33,34$ & $-75,15$ & $-79,68$ \\
\hline SE & $-70,50$ & $-88,25$ & -4262 & $-72,69$ & $-79,72$ & $-93,68$ \\
\hline
\end{tabular}

Fonte: MAPA (2017).

Como pode ser observado na tabela 3, a produção de mandioca também sofreu quedas em todos estados do SAB do Nordeste. Apenas os estados de Ceará e Sergipe tiveram produção positiva no ano de 2011, enquanto em Alagoas a produção foi positiva em 2012, mesmo que no ano anterior tenha sido negativa.

Tabela 3 - Produção de Mandioca no SAB - 2011-2016

\begin{tabular}{|l|r|r|r|r|r|r|r|}
\hline \multirow{3}{*}{ UF } & \multicolumn{7}{|c|}{ PRODUÇÃO (em mil t) } \\
\cline { 2 - 9 } & Média & $\mathbf{2 0 1 1}$ & $\mathbf{2 0 1 2}$ & $\mathbf{2 0 1 3}$ & $\mathbf{2 0 1 4}$ & $\mathbf{2 0 1 5}$ & $\mathbf{2 0 1 6}$ \\
& $\mathbf{2 0 0 9}$ & & & & & & \\
& \multicolumn{2}{|c|}{} & & & & & \\
\hline AL & 185,11 & 175,94 & 205,27 & 131,40 & 138,37 & 127,28 & 115,20 \\
\hline BA & $1.684,78$ & $1.469,74$ & 915,51 & 603,62 & 922,50 & $1.027,44$ & 810,64 \\
\hline CE & 365,84 & 440,13 & 188,94 & 165,12 & 251,83 & 139,43 & 160,20 \\
\hline MG & 274,39 & 251,70 & 232,40 & 208,47 & 209,33 & 203,17 & 200,85 \\
\hline PB & 85,24 & 71,93 & 45,65 & 35,74 & 31,08 & 37,18 & 36,97 \\
\hline PE & 577,94 & 448,58 & 311,79 & 273,46 & 280,17 & 355,00 & 116,51 \\
\hline PI & 304,55 & 200,70 & 127,80 & 40,17 & 42,86 & 128,49 & 80,34 \\
\hline RN & 402,70 & 251,43 & 195,59 & 58,10 & 146,88 & 133,84 & 84,59 \\
\hline SE & 77,48 & 78,14 & 70,61 & 65,01 & 57,41 & 41,23 & 37,01 \\
\hline
\end{tabular}

Fonte: MAPA (2017).

A seca de 2012-2017 representou perdas consideráveis na produção da mandioca, que é uma espécie muito consumida na região nordeste como um todo e um produto presente na alimentação do nordestino, em função dos preços praticados na economia regional. Observa-se na tabela 4 que em apenas um ano (2014) o Estado de Sergipe teve variação da produção positiva, tendo os demais anos e os demais estados variação da produção negativa.

Tabela 4 - Variação da Produção de Mandioca do SAB - 20112016

\begin{tabular}{|l|r|r|r|r|r|c|}
\hline \multirow{2}{*}{ UF } & \multicolumn{7}{|c|}{ Variação \% (base média 09/10) } \\
\cline { 2 - 8 } & $\mathbf{2 0 1 1}$ & $\mathbf{2 0 1 2}$ & $\mathbf{2 0 1 3}$ & $\mathbf{2 0 1 4}$ & $\mathbf{2 0 1 5}$ & $\mathbf{2 0 1 6}$ \\
\hline AL & $-4,96$ & 10,89 & $-29,01$ & $-25,25$ & $-31,24$ & $-37,76$ \\
\hline BA & $-12,76$ & $-45,66$ & $-64,17$ & $-45,25$ & $-39,02$ & $-51,88$ \\
\hline CE & 20,31 & $-48,36$ & $-54,87$ & $-31,16$ & $-61,89$ & $-56,21$ \\
\hline MG & $-8,27$ & $-15,30$ & $-24,02$ & $-23,71$ & $-25,96$ & $-26,80$ \\
\hline PB & $-15,62$ & $-46,45$ & $-58,07$ & $-63,54$ & $-56,38$ & $-56,62$ \\
\hline PE & $-22,38$ & $-46,05$ & $-52,68$ & $-51,52$ & $-38,58$ & $-79,84$ \\
\hline PI & $-34,10$ & $-58,04$ & $-86,81$ & $-85,93$ & $-57,81$ & $-73,62$ \\
\hline RN & $-37,56$ & $-51,43$ & $-85,57$ & $-63,53$ & $-66,76$ & $-78,99$ \\
\hline SE & 0,86 & $-8,87$ & $-16,09$ & 25,91 & $-46,79$ & $-52,24$ \\
\hline
\end{tabular}

Fonte: MAPA (2017).

Quanto à produção de milho, observa-se que não foi muito diferente das produções de feijão e mandioca no que diz respeito às perdas, que também foram significativas em todos estados na região SAB no período de 2011-2016. Embora o ano de 2011 
apresente perdas na maioria dos estados, estas produções têm perdas em todos os estados e em todos os anos do período 20122016.

Tabela 5 - Produção de Milho do SAB - 2011-2016

\begin{tabular}{|l|r|r|r|r|r|r|r|}
\hline \multirow{3}{*}{ UF } & \multicolumn{7}{|c|}{ PRODUÇÃO (em mil t) } \\
\cline { 2 - 9 } & $\begin{array}{l}\text { MÉDIA } \\
\mathbf{2 0 0 9 / 1 0}\end{array}$ & $\mathbf{2 0 1 1}$ & $\mathbf{2 0 1 2}$ & $\mathbf{2 0 1 3}$ & $\mathbf{2 0 1 4}$ & $\mathbf{2 0 1 5}$ & \multirow{2}{2016}{} \\
\hline AL & 28,33 & 29,77 & 0,46 & 6,56 & 8,51 & 13,32 & 4,10 \\
\hline BA & 677,86 & 420,96 & 86,87 & 593,80 & 354,73 & 609,13 & 231,14 \\
\hline CE & 335,42 & 856,98 & 102,16 & 102,09 & 320,03 & 114,78 & 98,41 \\
\hline MG & 73,75 & 59,75 & 41,07 & 36,60 & 67,13 & 57,88 & 65,12 \\
\hline PB & 51,29 & 55,43 & 3,09 & 13,81 & 19,40 & 6,42 & 9,71 \\
\hline PE & 125,07 & 117,02 & 18,83 & 20,42 & 47,51 & 23,96 & 10,84 \\
\hline PI & 96,85 & 167,15 & 12,05 & 18,32 & 38,88 & 46,69 & 22,70 \\
\hline RN & 235,28 & 451,26 & 24,89 & 101,27 & 119,47 & 31,93 & 19,51 \\
\hline SE & 714,69 & 468,25 & 267,68 & 652,56 & 715,29 & 457,04 & 109,47 \\
\hline
\end{tabular}

Fonte: IBGE/PAM - Elaboração SPA/MAPA (2017).

Quanto à variação da produção do milho a única exceção foi o Estado de Sergipe com fraca recuperação (de 0,08\%) no ano de 2014 e voltando a ter queda na produção nos anos de 2015-16. Ou seja, não houve produção significativa que representasse uma recuperação significativa dessa cultura (Tabela 6).

Tabela 6 - Variação da produção de milho no SAB - 2011-2016

\begin{tabular}{|c|c|c|c|c|c|c|}
\hline \multirow{2}{*}{ UF } & \multicolumn{7}{|c|}{ Variação \% (base média 09/10) } \\
\cline { 2 - 7 } & $\mathbf{2 0 1 1}$ & $\mathbf{2 0 1 2}$ & $\mathbf{2 0 1 3}$ & $\mathbf{2 0 1 4}$ & $\mathbf{2 0 1 5}$ & $\mathbf{2 0 1 6}$ \\
\hline AL & 5,08 & $-98,38$ & $-76,86$ & $-69,95$ & $-53,00$ & $-85,52$ \\
\hline BA & -37.90 & $-87,19$ & -12.40 & $-47,67$ & $-10,14$ & $-65,90$ \\
\hline CE & 155,49 & $-69,54$ & $-69,56$ & $-4,59$ & $-65,78$ & $-70,66$ \\
\hline MG & $-18,98$ & $-44,31$ & $-50,37$ & $-8,98$ & $-21,52$ & $-11,70$ \\
\hline PB & 8,08 & $-93,98$ & $-73,08$ & $-62,17$ & $-80,84$ & $-81,08$ \\
\hline PE & $-06,43$ & $-84,95$ & $-83,67$ & $-62,02$ & $-80,84$ & $-91,34$ \\
\hline PI & 72,59 & $-87,56$ & $-81,09$ & $-59,85$ & $-51,80$ & $-76,56$ \\
\hline RN & 91,80 & $-89,42$ & $-56,96$ & $-49,22$ & $-86,43$ & $-91,71$ \\
\hline SE & $-34,48$ & $-62,55$ & $-8,69$ & 0,08 & $-36,05$ & $-84,68$ \\
\hline
\end{tabular}

Fonte: IBGE/PAM - Elaboração SPA/MAPA (2017).

Por fim, deve-se destacar que todas as tabelas exibem uma quebra generalizada das safras durante o período 2012-2016 no SAB. Destacando-se a produção de feijão em Alagoas e Sergipe, que em 2016 tiveram quase a totalidade da produção dizimada nos municípios do semiárido, chegando a perdas de $97 \%$ e $94 \%$, respectivamente. Na Região Semiárido, com exceção de Minas Gerais, todos os estados tiveram perdas acima de 50\% na produção de feijão e perdas de quase toda produção de mandioca e milho em todos estados (MAPA, 2017).

Como dito ao longo do texto, as condições de seca impactaram também as condições naturais. A vegetação nativa teve perdas consideráveis, como é o caso das espécies de valor cultural e econômico como o umbuzeiro (Spondias tuberosa) representado na Figura 5.

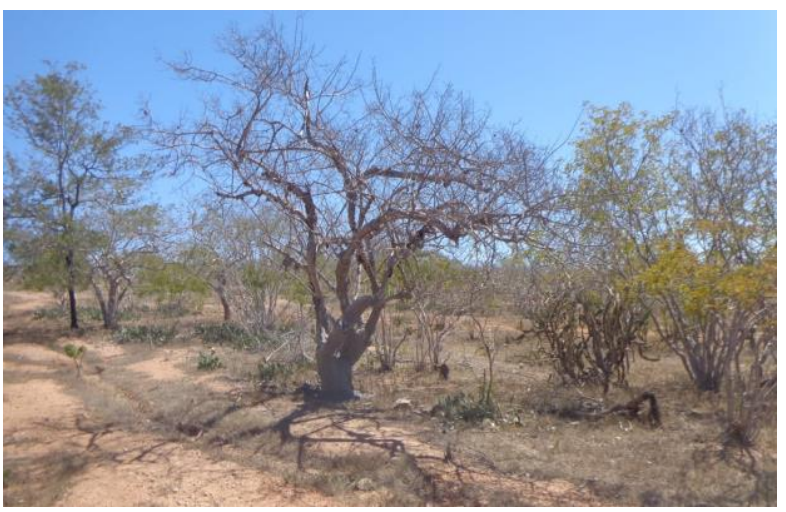

Figura 5 - Umbuzeiro morto na caatinga. Sítio Luiz Gomes em Caraúbas-PB, jun. de 2018. Foto gentilmente cedida por João Macedo Moreira em 2018.

Outra imagem que pode representar o quadro paisagístico da seca é o da região de Sento Sé na Bahia, com árvores e arbustos mortos e tombados pelo vento na caatinga degradada (Figura 6).

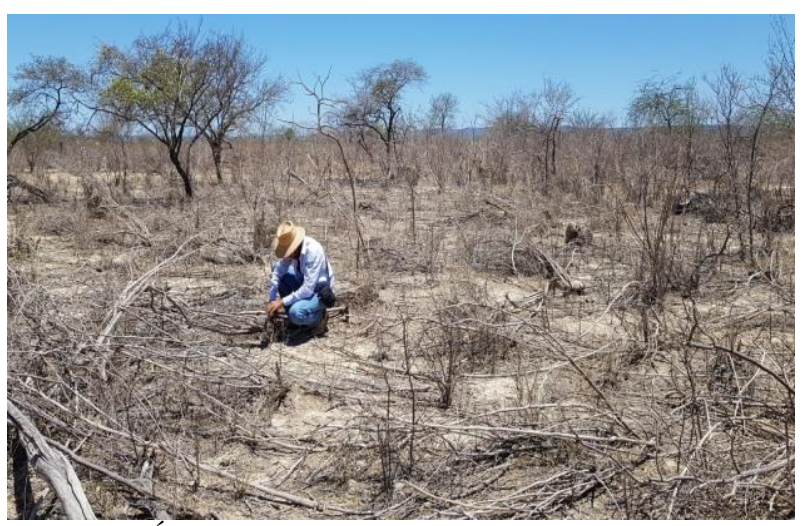

Figura 6 - Árvores e arbustos mortos e tombados pelo vento em caatinga degradada, 2017. Sítio Fartura, município de Sento Sé - BA. Foto gentilmente cedida por: João Macedo Moreira, 2018.

Desse quadro desolador da vegetação nativa, representado nas figuras, com espécies adaptadas as secas ao longo do séculos, não se espera que a agropecuária possa produzir a não ser que se criem as condições necessárias para viabilizar as culturas.

\section{CONSIDERAÇÕES FINAIS}

O fenômeno das secas é o tema principal das sociedades que vivem em terras secas, seja para o cidadão comum que vive nestas terras, seja o político ou empresário, assim como daqueles que lidam com a produção do conhecimento - o pesquisador. As secas como fenômeno climático, social e econômico sempre será motivo de preocupação da sociedade, uma vez que seus impactos são prejudiciais às atividades econômicas e a vida como um todo, refletindo-se na sobrevivência das populações por um tempo considerável, muitas vezes de duração imprevisível, porém não sendo duradoura como já é sabido pela ciência.

Aliar o conhecimento científico às políticas de estado sempre será necessário, uma vez que as medidas de mitigação dos 
impactos e a preparação aos fenômenos naturais requer uma população conhecedora e atuante nas crises (formação de cidadãos resilientes) em conjunto com o estado, num país onde a democracia deve ser a base da sociedade.

\section{REFERÊNCIAS}

ARAÚJO, Sérgio M. S. de. Crise hídrica na região de Campina Grande-PB. Palestra proferida na Semana de Geografia da UEPB. Campina Grande, 10 de agosto de 2016.

ARAÚJO, Sérgio M. S. de; LIMA, Eduardo V. R. de. A Paraíba, o semiárido paraibano e a desertificação. In: Araújo, Sérgio M. S. de: Lima, Eduardo V. R. de (Organizadores). Desertificação no Semiárido Brasileiro e Paraibano. Paulo Afonso-BA: Editora da Sociedade Brasileira de Ecologia Humana, 2019. p. 63-89.

AZEVEDO, Pedro V. de. Caracterização das secas. In: Bernardo Barbosa da Silva (Org.). Aplicações Ambientais Brasileiras com Geoprocessamento e Sensoriamento Remoto. Campina Grande: EDUFCG, 2013. p. 153-176.

BARRY, R. G.; CHORLEY, R. J. Atmosfera, tempo e clima. $9^{\mathrm{a}}$ Ed. Porto Alegre: Bookman, 2013. 512 p.

CASTRO, Antônio L. C.; CALHEIROS, L. B.; CUNHA, Maria I. R.; BRINGEL, Maria L. N. C. Manual de Desastres. Brasília: Ministério da Integração Nacional, 2003. Volume 1 - Desastres Naturais. 174 p.

GIRÃO, Osvaldo. Reconstrução do clima no nordeste brasileiro: secas e enchentes do século XIX. Finisterra, XLVII, 93, p. 29-47, 2012.

LIMA, José Roberto de; MAGALHÃES, Antônio Rocha. Secas no Nordeste: registros históricos das catástrofes econômicas e humanas do século 16 ao século 21. Parcerias Estratégicas, Brasília-DF, v. 23, n. 46, p. 191-212, jan.-jun., 2018.

MEDEIROS, Alexandre M. Teodosio de; BRITO, Antônio C. de. A seca no Estado da Paraíba - Impactos e ações de resiliência. Parcerias Estratégicas. Brasília-DF, v. 22, n. 44, p. 139-154, jan-jun, 2017.

MINISTÉRIO DA AGRICULTURA, PECUÁRIA E ABASTECIMENTO - MAPA. Informativo sobre a Estiagem no Nordeste - $n^{o}$ 113. Brasília: Ministério da Agricultura, Pecuária e Abastecimento/Secretaria de Política
Agrícola Departamento de Crédito e Estudos Econômicos/Coordenação-Geral de Estudos e Análises, 2017. 4 p.

MINISTÉRIO DO MEIO AMBIENTE - MMA. Atlas das áreas susceptíveis à desertificação do Brasil. Marcos Oliveira Santana (organizador). Brasília: MMA/Secretaria de Recursos Hídricos, Universidade Federal da Paraíba, 2007.

PEREIRA, Luís S. Recursos Hídricos, Secas e Desertificação. In: LOURO, Victor. Desertificação: sinais, dinâmicas $e$ sociedade. Lisboa: Instituto Piaget, 2004. p. 47-60.

RÊGO, André Heráclito. Os sertões e os desertos: o combate à desertificação. Brasília: FUNAG, 2012.

SUASSUNA, João. Gestão estratégica dos recursos hídricos no contexto do bioma Caatinga. Anais do II Simpósio do Bioma Caatinga; editores: Diogo Denardi Porto, Lúcia Helena Piedade Kiill. Petrolina: Embrapa Semiárido, 2018.

SUPERITENDÊNCIA DE DESENVOLVIMENTO DO NORDESTE - SUDENE. Resolução $N^{o} 115$, de 23 de novembro de 2017. Recife: SUDENE, 2017.

\section{AGRADECIMENTOS}

Agradecemos o convite dos organizadores do I Simpósio de Redução de Riscos dos Desastres na Região Nordeste e II Workshop do Grupo de Pesquisas de Gerenciamento dos riscos de Desastres - GENAT, tanto da participação na mesa quanto da oportunidade de publicação do texto no dossiê do evento na Revista de Geociências do Nordeste - REGNE.

Recebido em: 06/06/2020

Aceito para publicação em: 22/05/2021 